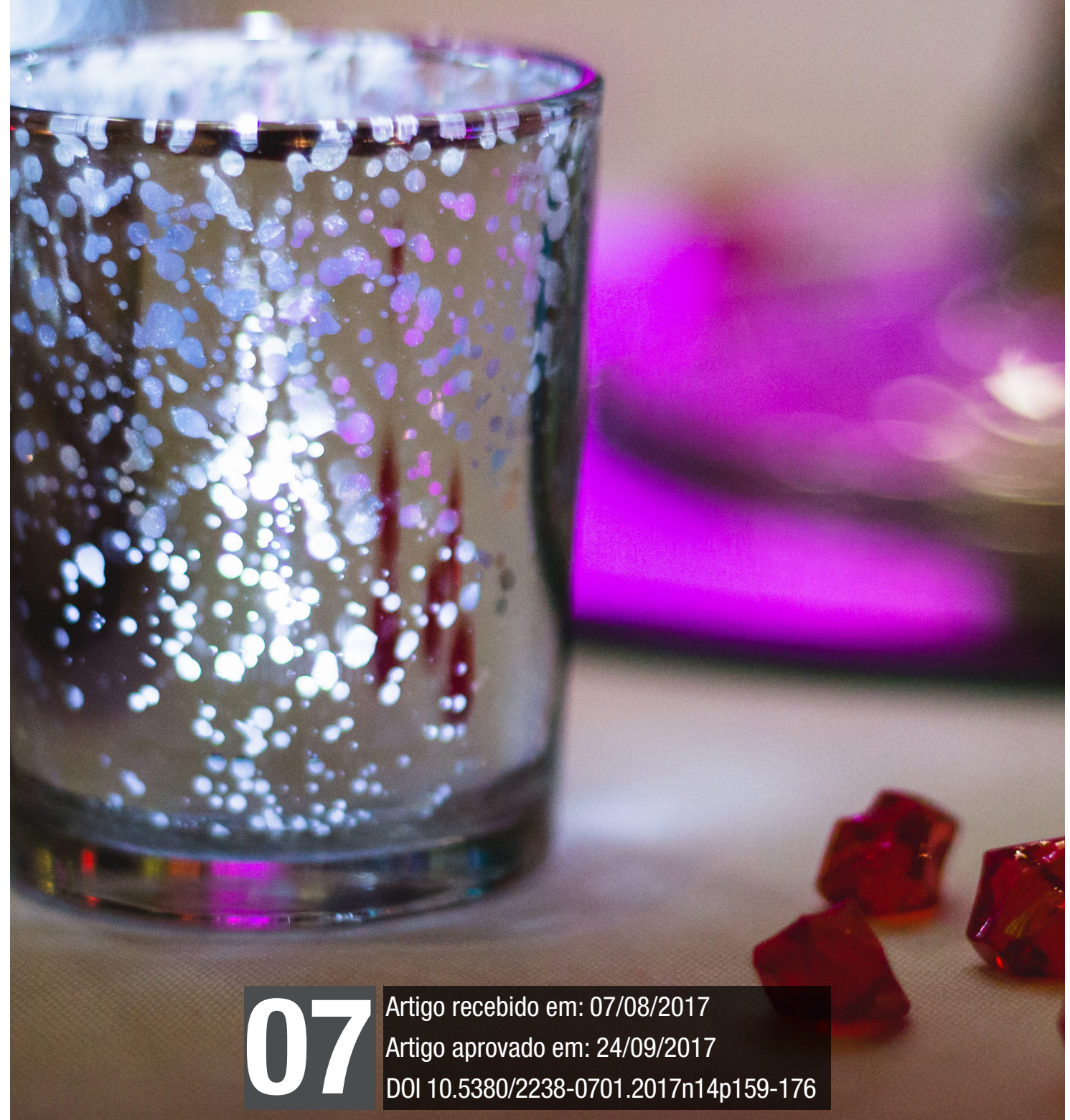


Felicidade. Consumo. Desenvolvimento. 


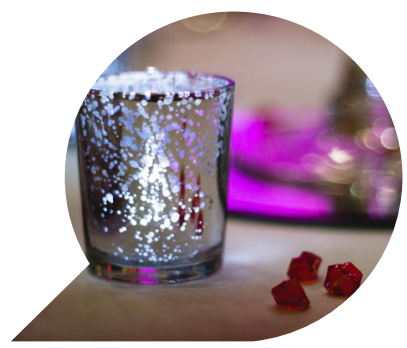

\section{O discurso publicitário da felicidade: conexões com o consumo e o desenvolvimento}

The advertising discourse of happiness: connections with con-
sumption and development

El discurso publicitario de la felicidad: conexiones con el consumo y el desarrollo

\begin{tabular}{c}
\hline CLÓVIS REIS $^{\star}$ \\
\hline CYNTHIA MORGANA BOOS DE QUADROS $^{* *}$ \\
\hline YANET REIMONDO BARRIOS \\
\end{tabular}

Resumo: A felicidade se transformou num ideal da cultura ocidental e se tornou quase um desejo obrigatório. O capitalismo construiu uma cultura da felicidade que por meio da publicidade estimula o hiperconsumo e leva à alienação, ao individualismo, e à infelicidade patológica. Partindo desse cenário, o objetivo des-

\footnotetext{
* Doutor em Comunicação (Universidad de Navarra, Espanha), professor titular do PPG em Desenvolvimento Regional da Fundação Universidade Regional de Blumenau (FURB). Dirige o Grupo de Pesquisa Estudos Midiáticos Regionais da FURB. E-mail: professorclovisreis@gmail.com

** Doutora em Desenvolvimento Regional pela Fundação Universidade Regional de Blumenau (FURB), professora Curso de Comunicação Social do Centro de Ciências Humanas e da Comunicação na Fundação Universidade Regional de Blumenau (FURB). E-mail: cynthiadequadros@gmail.com *** Formada em Comunicação Social pela Universidade da Habana em 2012, mestranda do PPG em Desenvolvimento Regional da Fundação Universidade Regional de Blumenau (FURB). Bolsista PECPG do CNPq. E-mail: yanet.barrios89@gmail.com
} 
te trabalho é discutir nexos entre a questão da felicidade, o consumo e os atuais padrões de desenvolvimento. Tal revisão indica que a sociedade contemporânea é guiada por um imperativo felicista nutrido pela economia capitalista, da qual a publicidade é um elemento estratégico, que incentiva a demanda crescente pelo consumo.

Palavras-chaves: Felicidade; Consumo; Desenvolvimento.

Abstract: Happiness has become an ideal of Western culture and almost an obligatory desire. Capitalism has built a culture of happiness, which through advertising, stimulates hyperconsumption and leads to alienation, individualism, and pathological unhappiness. Starting from this scenario, the objective of this work is to discuss nexus between the issue of happiness, consumption and current patterns of development. Such a review indicates that contemporary society is guided by a felicist imperative nurtured by the capitalist economy, of which advertising is a strategic element, which encourages the increasing demand for consumption.

Key words: Happiness; Consumption; Development.

Resumen: La felicidad se ha convertido en un ideal de la cultura occidental y se ha vuelto casi un deseo obligatorio. El capitalismo construyó una cultura de la felicidad que por medio de la publicidad estimula el hiperconsumo y lleva a la alienación, al individualismo, y a la infelicidad patológica. A partir de ese escenario, el objetivo de este trabajo es discutir nexos entre la cuestión de la felicidad, el consumo y los actuales patrones de desarrollo. Tal revisión indica que la sociedad contemporánea es guiada por un imperativo felicista nutrido por la economía capitalista, de la cual la publicidad es un elemento estratégico, que incentiva la demanda creciente por el consumo.

Palabras clave: Felicidad; Consumo; Desarrollo. 


\section{Introdução}

Na sociedade do século XXI - norteada pelo estilo de vida capitalista -, a lógica econômica concilia felicidade e poder de compra (SCHOPENHAUER, 2006). O imaginário coletivo da felicidade é ativado por uma avalanche de informações lançadas pela mídia, procurando convencer os sujeitos de que a realização plena está na aquisição de bens materiais e orquestrando a sociedade do hiperconsumo (LIPOVETSKY, 2007). A publicidade aparece como elemento estratégico desse processo (BAUDRILLARD, 1995), intrínseco ao que Guy Debord (2003) denomina sociedade do espetáculo, na qual o mundo da mercadoria domina tudo o que é vivido.

No mundo globalizado a felicidade encontrou "nas sociedades de hoje e no espaço de circulação discursivo da mídia, o seu simulacro: o consumo" (MEDEIROS, 2009, p. 42). A mídia é uma entidade onipresente, ditando a ordem social e determinando modos de vida, comportamentos e crenças. Para Baudrillard (1995), é por esse meio que se constitui a sociedade de consumo, que invade a vida privada e as relações sociais, traçando o perfil das satisfações pessoais. $\mathrm{O}$ autor enfatiza que "a publicidade é antes consumida do que destinada a dirigir o consumo” (BAUDRILLARD, 1995, p. 182). É ela que seduz os consumidores, que os encanta com um discurso que atua no plano das crenças e dos desejos.

Tentando entender a ambiguidade de uma época em que a felicidade é valor máximo, mas carrega consigo inúmeras aflições do espírito, Lipovetsky (2007) cria a tese de que, na sociedade de hiperconsumo, essa felicidade é paradoxal. De um lado, estão dadas as condições para que as aspirações individuais sejam satisfeitas pelo mercado; de outro, também estão postos os obstáculos que se contrapõem à postura hedonista do indivíduo contemporâneo. O hiperconsumidor tem acesso ao ter, mas aspira a ser. É um ser que busca a felicidade em coisas e emoções, assim como os relacionamentos afetivos, que se desmancham rapidamente, seja por medo ou por insegurança (BAUMAN, 2004). Para Bittencourt (2009), os consumidores a creditam que a felicidade pode ser adquirida mediante a adequação pessoal a critérios mercadológicos e aos estímulos viciosos da moda, consumindo-se e descartando-se cada vez mais, sejam coisas ou mesmo pessoas.

Este trabalho constitui parte de uma tese de doutorado, cujo propósito visou evidenciar e analisar nexos entre noções de felicidade e 
padrões de desenvolvimento. A originalidade deste estudo consiste, justamente, no exame das conexões entre felicidade e desenvolvimento, que procura revelar interfaces relevantes e que guardam relação com o tema investigado.

\section{Felicidade: múltiplos sentidos, diferentes interpretações}

Uma grande crítica ao capitalismo é a construção de uma sociedade pautada no espetáculo e no hiperconsumo, ancorando seu discurso em promessas de felicidade. Nunca se falou tanto nas conexões entre felicidade, consumo e desenvolvimento como neste século. A felicidade se transformou num ideal da cultura ocidental e se tornou quase um desejo obrigatório que rege a organização social. A cultura do século XXI direciona holofotes para o direito à busca da felicidade, que está mencionado em textos constitucionais de países como França (1958), Japão (1947), Coreia do Sul (1948) e Butão (2008) e é inclusive objeto de resolução da Organização das Nações Unidas (ONU), que sugere que os governos elaborem políticas públicas visando à felicidade das pessoas.

Multiplicam-se, em todos os campos de interesse humano, os estudos que relacionam felicidade com os padrões atuais de desenvolvimento e neles se evidencia um consenso sobre a necessidade de mudar os hábitos de consumo, os indicadores de riqueza e as formas de mensuração do desenvolvimento socioeconômico. São essas constatações, aliadas ao entendimento de que existe uma relação perversa entre aumento da riqueza (renda) e felicidade, que incitam o interesse de economistas e estudiosos de outras áreas em discutir a necessidade de avaliar o progresso das sociedades, indo além dos tradicionais indicadores econômicos, como o Produto Interno Bruto (PIB) e o Índice de Desenvolvimento Humano (IDH).

Para dar uma resposta às críticas lançadas contra o PIB e o IDH, a ONU busca um modelo capaz de aprimorá-los, tomando por base o indicador de Felicidade Interna Bruta (FIB), cujo conceito foi criado em 1972 por Jigme Singye Wangchuck, o quarto rei do Butão. Ao contrário de certos conceitos atuais de felicidade encontrados na literatura ocidental, a FIB parte do pressuposto de que a felicidade é em si multidimensional. É uma medida construída a partir de dados extraídos de pesquisas periódicas que permitem que os resultados de uma amostragem representativa possam ser decompostos em vários níveis subnacionais. Ele fornece uma visão geral de performances em nove do- 
mínios da FIB: bem-estar psicológico, saúde, uso do tempo, educação, diversidade cultural e resiliência, boa governança, vitalidade comunitária, diversidade e resiliência ecológica, padrão de vida (URA; ALKIRE; ZANGMO, 2012).

Pautada principalmente na proposta do Butão, a Assembleia Geral das Nações Unidas aprovou, em 2011, uma resolução, intitulada Happiness: towards a holistic approach to development (A felicidade: para um enfoque holístico do desenvolvimento), na qual declara que a felicidade é um objetivo e uma aspiração universal que deve ser potencializada. Aponta também a busca pela felicidade como um objetivo humano fundamental e convida os países membros da ONU a promoverem novas medidas que reflitam melhor a importância desse objetivo em suas políticas públicas. $\mathrm{O}$ texto acentua que a comunidade internacional deve reconhecer a necessidade de aplicar ao crescimento econômico um enfoque mais inclusivo, equitativo e equilibrado - o que significa que os padrões de consumo deverão ser modificados para que os sistemas biológicos consigam renovar-se de modo a sustentar os processos produtivos -, promover o desenvolvimento sustentável, a erradicação da pobreza, a felicidade e o bem-estar de todos os povos.

Nesse mesmo contexto, no qual a felicidade se apresenta como direito, emerge uma ordem social implícita, como uma obrigação, para ser feliz a qualquer preço. Esse desejo interiorizado de felicidade, muitas vezes associado a uma insatisfação emocional crônica, leva as pessoas ao ímpeto de consumir, como se a aquisição de objetos materiais conduzisse à felicidade (COSTA, 2005). Opera aqui a lógica econômica que concilia felicidade e poder de compra, e o consumismo acaba preenchendo o vazio existencial do ser humano. Trabalhar mais para consumir mais se tornou um dogma da doutrina capitalista, da religião do capital. Os padrões de desenvolvimento capitalista construíram uma cultura da felicidade que estimula o consumo desenfreado, estimulado pela publicidade e pela mídia, e faz crescer um mercado cada vez mais voraz. Ser feliz passou a ser um mandamento que relega à vergonha ou à inferioridade aqueles que não se adequam a esse imperativo felicista (BAUMAN, 2010).

Dessa forma, parece até que as pessoas são obrigadas a ser felizes e para isso têm que seguir padrões e receitas para criar novos modos de estar no mundo, de pensar, sentir e agir, ou seja, seguir estilos de vida aos moldes do capital. E a publicidade se encarrega de aquecer a dinâmica de consumo. O poder do discurso publicitário felicista, escorado na mí- 
dia e nos interesses do capital, oferece condições para que a produção de mercadorias assuma o domínio total da economia. A influência da mídia sobre o comportamento das pessoas traduz a busca pela satisfação em diferentes aspectos da existência. É no palco montado pelos meios de comunicação de massa que o espetáculo da mercadoria - no mesmo ritmo veloz e com a mesma força implacável de sedução da mídia e da publicidade - apresenta como protagonista o bem descartável e, como figurante, a felicidade, que parece sempre escapar à visão do espectador.

No campo do discurso publicitário - catalisador de negócios e ativador de desejos - isso se confirma: seu poder, escorado na mídia e nos interesses do capital, ofereceu condições para que a produção de mercadorias, antes apenas a troca de produtos diferentes entre produtores independentes, "assumisse o domínio total da economia. A economia toda tornou-se então o que a mercadoria tinha mostrado ser durante essa conquista: um processo de desenvolvimento quantitativo" (DEBORD, 1997, p. 29). E não seria esse fenômeno justamente a meta do capitalismo, cujo alcance se daria, em grande medida, com apoio da publicidade e da mídia: o crescimento quantitativo da produção e do consumo?

Cristiana Campos e Solange Souza (2003) acentuam que objetos e mercadorias são usados para demarcar as relações sociais e determinam estilos de vida, posição social, além da maneira de as pessoas interagirem socialmente. Nos palcos, vitrines, passarelas e vídeos da sociedade do espetáculo desfilam padrões de beleza, corpos esculturais, parecendo até à prova de velhice e isentos de qualquer imperfeição, gente bonita, rica e famosa. $\mathrm{O}$ desejo de se parecer com um desses personagens cultuados pela mídia e endeusados em peças publicitárias conduz à busca por consumo e por padrões de beleza e de comportamento que se adequem ao que é visto, muitas vezes sem ao menos se perceber a intenção subliminar das imagens que a publicidade utiliza para incentivar e legitimar o consumo.

Nesse movimento, as moléculas do individualismo e do narcisismo fluem rapidamente, "guias e métodos para viver melhor fervilham, a televisão e os jornais destilam conselhos de saúde e de forma, os psicólogos ajudam os casais e os pais em dificuldade, os gurus que prometem a plenitude multiplicam-se" (LIPOVETSKY, 2007, p. 336). A sociedade de consumo se transforma na sociedade da miséria material e psicológica (RICO, 2007), abrindo caminho para o avanço da indústria cultural 
(HORKHEIMER; ADORNO, 1985) - território onde tudo se torna negócio, com fins comerciais realizados por meio de sistemática e programada exploração de bens considerados culturais.

Impulsionada pela crescente demanda por medidas paliativas que prometem emancipar o homem de seus males, muitos deles provocados pela obrigação de ser feliz (BRUCKNER, 2002), a indústria cultural expande seus domínios com uma produção ilimitada de livros de autoajuda que, na definição de Romão (2009), são produtos semiculturais cujo conteúdo é invariavelmente pontuado por frases feitas e histórias sem profundidade que beiram o risível. Esse tipo de leitura promove "um desligamento da realidade concreta, aventando a emergência de uma instância iluminada pelo pensamento positivo, místico, sagrado, pelo afeto, sucesso e felicidade" (ROMÃO, 2009, p. 64). Ao oferecer receitas prontas e apagar a dúvida e a crítica em torno delas, os livros de autoajuda vendem ilusões e fantasias. A mais gritante delas está no fato de propor que "todos igualmente têm o mesmo poder numa sociedade crivada de injustiças, assimetrias de poder, diferenças entre classes sociais" (ROMÃO, 2009, p. 65).

Segundo Brunelli (2008), o discurso da autoajuda é altamente favorável à ideologia capitalista porque evita reflexões profundas sobre o existir e sobre coisas negativas, prestando-se mais a aconselhar do que a filosofar sobre os problemas individuais e sociais cotidianos; oferece receitas e segredos para solucionar problemas existenciais, ignorando as suas causas. E é justamente isso que sugerem os títulos dos livros desse gênero: a oferta de fórmulas prontas com maneiras de como preparar que equivalem a passos a serem seguidos. É uma literatura que se alimenta da busca pela felicidade e vende receitas para alcançá-la, abarcando todos os domínios da vida e prescrevendo antídotos para todos os venenos. Desde as ações humanas mais corriqueiras, como se alimentar, dormir, relaxar, até "seduzir, fazer amor, comunicar-se com os filhos, conservar o dinamismo: qual esfera ainda escapa às receitas da felicidade? ", questiona Lipovetsky (2007, p. 336).

Para Francisco Rüdinger (2003), os tratados e manuais que, por meio de uma linguagem prescritiva, ensinam como vencer na vida e procuram dar lições sobre crescimento pessoal, constituem-se como dispositivos por meio dos quais as "massas urbanas articulam sua conversão ao individualismo" (RÜDGER, 2010, p. 238.). O autor considera a alta demanda por essa literatura como a expressão do 
isolamento e do subjetivismo que marcam uma sociedade contemporânea também egocentrista, individualista, que nutre o hiperconsumismo solitário e narcísico.

Todo esse roteiro do teatro consumista pode mudar se novos modos de produção econômica - nos quais as pessoas sejam os atores principais, vistas como protagonistas do seu próprio futuro -, forem implantados, como idealizam Max-Neef, Elizalde e Hopenhayn (2012) em sua proposta de desenvolvimento à escala humana, que segue alguns postulados fundamentais, entre eles o de que a economia está para servir as pessoas e não as pessoas para servirem a economia e o de que o desenvolvimento se refere às pessoas, não às coisas. Os mesmos autores indicam que não existe uma fórmula mágica para ser totalmente feliz, mas é possível buscá-la a partir da satisfação de necessidades básicas que são invariáveis e universais. $\mathrm{O}$ que se modifica com o tempo ou de um quadro cultural para a outro são os modos ou meios empregados para a satisfação delas.

Max-Neef, Elizalde e Hopenhayn (2012) afirmam que cada necessidade pode ser satisfeita em níveis diferentes e com intensidades distintas e em três contextos: com relação ao próprio indivíduo, com relação ao grupo social e com relação ao meio ambiente. O que muda através do tempo são os satisfatores, que estão relacionados a tudo aquilo que, por representar formas de Ter, Ser, Fazer e Estar, contribui para o atendimento das necessidades humanas; podem incluir estrutura política, práticas sociais, valores e normas, comportamentos e atitudes, tudo o que está em permanente estado de tensão entre consolidação e mudança. Nessa dinâmica, os bens econômicos são objetos ou artefatos que afetam a eficiência de um satisfator, alterando os limites de satisfação de uma necessidade, tanto positiva quanto negativamente.

O quadro 1 apresenta a matriz de necessidades e satisfatores desta forma: Coluna Ser: atributos pessoais ou coletivos expressados por substantivos; Coluna Ter: instituições, normas, mecanismos, ferramentas (não no sentido material), leis; Coluna Fazer: ações pessoais ou coletivas. Estar: locais e meios como tempo e espaço. 
Quadro 1 - Matriz de necessidades e satisfatores

\begin{tabular}{|c|c|c|c|c|}
\hline & Ser & Ter & Fazer & Estar \\
\hline Subsistência & $\begin{array}{l}\text { 1/ } \\
\text { Saúde física, saúde } \\
\text { mental, equilíbrio, } \\
\text { solidariedade, senso } \\
\text { de humor, } \\
\text { adaptabilidade }\end{array}$ & $\begin{array}{l}\text { 2/ } \\
\text { Alimento, abrigo, } \\
\text { trabalho }\end{array}$ & $\begin{array}{l}\text { A/ } \\
\text { descansar, trabalhar }\end{array}$ & $\begin{array}{l}\text { Meio ambiente, } \\
\text { meio social }\end{array}$ \\
\hline Proteção & $\begin{array}{l}\text { 5/ } \\
\text { Cuidado, } \\
\text { adaptabilidade, } \\
\text { autonomia, equilíbrio, } \\
\text { solidariedade }\end{array}$ & $\begin{array}{l}\text { 6/ } \\
\text { Sistema de seguro, } \\
\text { poupança, seguro } \\
\text { social, sistema de } \\
\text { saúde, família, } \\
\text { direitos } \\
\end{array}$ & $\begin{array}{l}\text { 7/ } \\
\text { Cooperar, prevenir, } \\
\text { planejar, cuidar, } \\
\text { curar, defender }\end{array}$ & $\begin{array}{l}\text { 8/ } \\
\text { Espaço onde se } \\
\text { mora, ambiente } \\
\text { social, habitação }\end{array}$ \\
\hline Afeto & $\begin{array}{l}\text { 9/ } \\
\text { Autoestima, } \\
\text { solidariedade, } \\
\text { respeito, tolerância, } \\
\text { generosidade, } \\
\text { receptividade, paixão, } \\
\text { determinação, } \\
\text { sensualidade, senso } \\
\text { de humor }\end{array}$ & $\begin{array}{l}\text { 10/ } \\
\text { Legislação, } \\
\text { amizade, família, } \\
\text { parcerias, animais } \\
\text { domésticos, } \\
\text { plantas, jardins, } \\
\text { relações com a } \\
\text { natureza }\end{array}$ & $\begin{array}{l}\text { 11/ } \\
\text { Fazer amos, } \\
\text { acariciar, expressar } \\
\text { emoções, } \\
\text { compartilhar, } \\
\text { cuidar, cultivar, } \\
\text { apreciar }\end{array}$ & $\begin{array}{l}\text { 12/ } \\
\text { Privacidade, } \\
\text { intimidade, lar, } \\
\text { espaço de } \\
\text { encontro }\end{array}$ \\
\hline Entendimento & $\begin{array}{l}\text { 13/ } \\
\text { Consciência crítica, } \\
\text { receptividade, } \\
\text { curiosidade, espanto, } \\
\text { disciplina, intuição, } \\
\text { racionalidade }\end{array}$ & $\begin{array}{l}14 / \\
\text { Literatura, } \\
\text { professores, } \\
\text { métodos, políticas } \\
\text { educacionais, } \\
\text { políticas de } \\
\text { educação }\end{array}$ & $\begin{array}{l}15 / \\
\text { Investigar, estudar, } \\
\text { experimentar, } \\
\text { educar, analisar, } \\
\text { meditar, interpretar }\end{array}$ & $\begin{array}{l}\text { 16/ } \\
\text { Ambientes de } \\
\text { interação } \\
\text { formativa, } \\
\text { escolas, } \\
\text { universidades, } \\
\text { academias, } \\
\text { grupos de } \\
\text { comunidade, } \\
\text { família }\end{array}$ \\
\hline Participação & $17 /$ & $18 /$ & $19 /$ & $20 /$ \\
\hline & $\begin{array}{l}\text { Adaptabilidade, } \\
\text { receptividade, } \\
\text { solidariedade, } \\
\text { vontade, } \\
\text { determinação, } \\
\text { dedicação, respeito, } \\
\text { paixão, senso de } \\
\text { humor }\end{array}$ & $\begin{array}{l}\text { Direitos, } \\
\text { responsabilidades, } \\
\text { obrigações, } \\
\text { privilégios, } \\
\text { trabalho }\end{array}$ & $\begin{array}{l}\text { Filiar-se, cooperar, } \\
\text { propor, } \\
\text { compartilhar, } \\
\text { divergir, acatar, } \\
\text { interagir, } \\
\text { concordar, } \\
\text { expressar opiniões }\end{array}$ & $\begin{array}{l}\text { Ambientes de } \\
\text { interação } \\
\text { participativa, } \\
\text { festas, } \\
\text { comunidades, } \\
\text { vizinhança, } \\
\text { família }\end{array}$ \\
\hline Ociosidade & $\begin{array}{l}21 / \\
\text { Curiosidade, } \\
\text { receptividade, } \\
\text { imaginação, } \\
\text { despreocupação, } \\
\text { sentido de humor, } \\
\text { tranquilidade, } \\
\text { sensualidade }\end{array}$ & $\begin{array}{l}22 / \\
\text { Jogos, espetáculos, } \\
\text { clubes, festas, paz } \\
\text { de espírito }\end{array}$ & $\begin{array}{l}\text { 23/ } \\
\text { Divagar, sonhar, } \\
\text { lembrar dos velhos } \\
\text { tempos, mergulhar } \\
\text { em fantasias, } \\
\text { relembrar, relaxar, } \\
\text { divertir-se, brincar }\end{array}$ & $\begin{array}{l}\text { 24/ } \\
\text { Privacidade, } \\
\text { intimidade, } \\
\text { espaços de } \\
\text { encontro, tempo } \\
\text { livre, espaço que } \\
\text { nos rodeia, } \\
\text { paisagens }\end{array}$ \\
\hline
\end{tabular}




\begin{tabular}{|c|c|c|c|c|}
\hline Participação & $\begin{array}{l}\text { 17/ } \\
\text { Adaptabilidade, } \\
\text { receptividade, } \\
\text { solidariedade, } \\
\text { vontade, } \\
\text { determinação, } \\
\text { dedicação, respeito, } \\
\text { paixão, senso de } \\
\text { humor }\end{array}$ & $\begin{array}{l}18 / \\
\text { Direitos, } \\
\text { responsabilidades, } \\
\text { obrigações, } \\
\text { privilégios, } \\
\text { trabalho }\end{array}$ & $\begin{array}{l}\text { 19/ } \\
\text { Filiar-se, cooperar, } \\
\text { propor, } \\
\text { compartilhar, } \\
\text { divergir, acatar, } \\
\text { interagir, } \\
\text { concordar, } \\
\text { expressar opiniões }\end{array}$ & $\begin{array}{l}\text { 20/ } \\
\text { Ambientes de } \\
\text { interação } \\
\text { participativa, } \\
\text { festas, } \\
\text { comunidades, } \\
\text { vizinhança, } \\
\text { família }\end{array}$ \\
\hline Ociosidade & $\begin{array}{l}\text { 21/ } \\
\text { Curiosidade, } \\
\text { receptividade, } \\
\text { imaginação, } \\
\text { despreocupação, } \\
\text { sentido de humor, } \\
\text { tranquilidade, } \\
\text { sensualidade }\end{array}$ & $\begin{array}{l}22 / \\
\text { Jogos, espetáculos, } \\
\text { clubes, festas, paz } \\
\text { de espírito }\end{array}$ & $\begin{array}{l}\text { 23/ } \\
\text { Divagar, sonhar, } \\
\text { lembrar dos velhos } \\
\text { tempos, mergulhar } \\
\text { em fantasias, } \\
\text { relembrar, relaxar, } \\
\text { divertir-se, brincar }\end{array}$ & $\begin{array}{l}\text { 24/ } \\
\text { Privacidade, } \\
\text { intimidade, } \\
\text { espaços de } \\
\text { encontro, tempo } \\
\text { livre, espaço que } \\
\text { nos rodeia, } \\
\text { paisagens }\end{array}$ \\
\hline Criação & $\begin{array}{l}25 / \\
\text { Paixão, determinação, } \\
\text { intuição, imaginação, } \\
\text { ousadia, } \\
\text { racionalidade, } \\
\text { autonomia, } \\
\text { inventividade, } \\
\text { curiosidade }\end{array}$ & $\begin{array}{l}26 / \\
\text { Destrezas, } \\
\text { habilidades, } \\
\text { métodos, trabalho }\end{array}$ & $\begin{array}{l}27 / \\
\text { Trabalhar, inventar, } \\
\text { construir, desenhar, } \\
\text { compor, interpretar }\end{array}$ & $\begin{array}{l}\text { 28/ } \\
\text { Ambientes de } \\
\text { produção e } \\
\text { informação, } \\
\text { "workshops", } \\
\text { grupos culturais, } \\
\text { audiências, } \\
\text { espaços para } \\
\text { expressão, } \\
\text { liberdade } \\
\text { temporal }\end{array}$ \\
\hline Identidade & $\begin{array}{l}\text { 29/ } \\
\text { Sensação de } \\
\text { pertencer, } \\
\text { consistência, } \\
\text { diferenciação, } \\
\text { autoestima, } \\
\text { assertividade }\end{array}$ & $\begin{array}{l}30 / \\
\text { Símbolos, } \\
\text { linguagem, } \\
\text { religião, hábitos, } \\
\text { costumes, grupos } \\
\text { de referência, } \\
\text { sexualidade, } \\
\text { valores, normas, } \\
\text { memória histórica, } \\
\text { trabalho }\end{array}$ & $\begin{array}{l}31 / \\
\text { Comprometer-se, } \\
\text { integrar-se, } \\
\text { confrontar-se, } \\
\text { conhecer a si } \\
\text { próprio, } \\
\text { reconhecer-se, } \\
\text { crescer }\end{array}$ & $\begin{array}{l}32 / \\
\text { Ritmos sociais, } \\
\text { ambientes do } \\
\text { cotidiano, } \\
\text { ambientes aos } \\
\text { quais } \\
\text { pertencemos, } \\
\text { estágios de } \\
\text { amadurecimento }\end{array}$ \\
\hline Liberdade & $\begin{array}{l}\text { 33/ } \\
\text { Autonomia, } \\
\text { autoestima, } \\
\text { determinação, paixão, } \\
\text { assertividade, } \\
\text { abertura de mente, } \\
\text { ousadia, rebeldia, } \\
\text { tolerância }\end{array}$ & $\begin{array}{l}34 / \\
\text { Igualdade de } \\
\text { direitos }\end{array}$ & $\begin{array}{l}\text { 35/ } \\
\text { Discordar, escolher, } \\
\text { diferenciar-se, } \\
\text { arriscar, } \\
\text { desenvolver a } \\
\text { consciência, } \\
\text { comprometer-se, } \\
\text { desobedecer, } \\
\text { meditar }\end{array}$ & $\begin{array}{l}36 / \\
\text { Plasticidade } \\
\text { espaço-temporal }\end{array}$ \\
\hline
\end{tabular}

Fonte: Max-Neef, Elizalde e Hopenhayn (2012, p. 41-42) 
É claro que ter muito dinheiro nunca tornou ninguém infeliz, mas em tempos antigos, Epicuro (1993) já dizia que o grau de felicidade não aumentaria com o aumento da riqueza. Segundo Max-Neef (2007), os Estados Unidos são um claro exemplo disso, porque, apesar de o poder aquisitivo ter quase triplicado de 1930 a 1995, o número de pessoas identificadas como muito felizes permaneceu quase invariável. Sachs (2012) confirma essa informação, ressaltando que o PIB per capita dos Estados Unidos triplicou desde 1960, enquanto as medidas de felicidade média permaneceram essencialmente inalteradas nos últimos cinquenta anos, evidenciando que maiores rendas médias não necessariamente melhoram o bem-estar médio dos indivíduos.

É esse o ponto nevrálgico da sociedade do crescimento: o domínio de uma economia de crescimento antropofágico que tende a absorvê-la, uma sociedade insustentável que produz aumento das desigualdades e injustiças, cria um bem-estar ilusório, "não suscita uma sociedade amigável e sim uma antissociedade que padece de sua riqueza" (LATOUCHE, 2012, p. 45). Para Furtado (1996), essa é a prova definitiva de que o desenvolvimento econômico - a ideia de que os povos pobres podem algum dia desfrutar das formas de vida dos atuais povos ricos - é simplesmente irrealizável. Nesse sentido, o autor indica que "a nova orientação do desenvolvimento teria que ser num sentido muito mais igualitário [...] reduzindo o desperdício provocado pela extrema diversificação dos [...] padrões de consumo privado dos grupos privilegiados" (FURTADO, 1996, p. 74).

A respeito dessa problemática, Löwy (2009) salienta que o modo de produção e de consumo dos países capitalistas avançados, fundado na lógica de acumulação ilimitada - e consequentemente na manutenção e no agravamento da gritante desigualdade entre o Norte e o Sul -, "de desperdício dos recursos, de consumo ostentatório e de destruição acelerada do meio ambiente, não pode de modo algum ser estendido ao conjunto do planeta, sob pena de crise ecológica maior" (LÖWY, 2009, p. 135).

Diante de tantas incongruências, o ideal desenvolvimentista de prosperidade e progresso apregoado no discurso capitalista se torna cada vez mais longe de ser realizado (SACHS, 2000). E essa situação denuncia que o projeto de um desenvolvimento econômico planejado para ser expandido por todo o mundo falhou e para Norgaard (1994), os princípios básicos em torno dos quais a transformação moderna foi concebida e implementada, enganaram-nos. 
As considerações até aqui apresentadas fazem lembrar o discurso proferido pelo cacique Seattle, chefe das tribos Suquamish e Duwamish, de Washington, quando, em 1854, o presidente dos Estados Unidos, Francis Pierce, tentava convencê-lo a vender suas terras para dar prosseguimento à ocupação do território estadunidense com populações estrangeiras que chegavam ao país: "Como pode-se comprar ou vender o céu, o calor da terra? Tal ideia é estranha. Nós não somos donos da pureza do ar ou do brilho da água. Como pode então comprá-los de nós? ” (GASSENFERTH, 2015, p. 5).

Uma mudança de rota para tomar o caminho de outro desenvolvimento implica uma transformação do insustentável padrão de consumo do capitalismo moderno, pautado na obsolescência planificada dos objetos de consumo (LÖWY, 2012). Ressalta Lesbaupin (2012) que é mais do que nunca o momento de pensar em um modelo de desenvolvimento centrado nas necessidades humanas, que garanta a reprodução da natureza, evite o desperdício e não esgote os bens de que precisamos para viver. Um desenvolvimento que, segundo ele, "esteja voltado para a vida e não para a maximização do consumo. É fundamental mudar isso [...], é urgente, é inadiável” (LESBAUPIN, 2012, p. 38).

\section{Considerações finais}

Nunca se falou tanto em felicidade nem se procurou tanto analisá-la a partir de diferentes perspectivas como nos tempos contemporâneos. Sua banalização no contexto capitalista, vinculado à sociedade do espetáculo e do consumo, tem construído novas percepções sobre o que é ser feliz. As relações humanas ficam cada vez mais fragilizadas e as pessoas, transformadas em turboconsumidores, avaliando tudo em temos de custos e benefícios, inclusive os afetos, estão constantemente sujeitas a ansiedade e frustrações $\bigotimes$ sintomas de uma infelicidade patológica. Nesse sentido, a infelicidade funciona como um estimulante do consumo: comprar é uma suspensão da angústia, um antídoto da solidão. Escolher a facilidade simplista do consumo como fonte de satisfação significa esconder a face da realidade que não se quer ver.

No meio dessa controvérsia, há quem acredite, como Max-Neef (1991), que todos os seres humanos têm necessidades básicas similares que podem levar à desejada felicidade, sem ser preciso ostentar luxo, mas para isso é preciso romper com padrões capitalistas cujo motor é a 
economia das compras sem limites que acaba levando ao individualismo, ao narcisismo, ao consumismo solitário. Mais que uma obrigação, os seres humanos precisam entender que a busca da felicidade é um direito de todos. E a cultura do século XXI lança suas luzes sobre esse direito, mencionado em textos constitucionais de vários países.

A análise mostrou que a sociedade contemporânea é guiada por um imperativo felicista nutrido pela economia capitalista que incentiva a demanda crescente por consumo. Há uma busca de felicidade a todo custo, como se fosse uma obrigação ser feliz. Assim como os discursos felicistas, as tramas e estratégias discursivas empregadas para propagação da ideologia capitalista do desenvolvimento, destituídos de neutralidade, funcionam como mecanismos de dominação cultural.

Resta saber de que forma os atuais padrões de desenvolvimento, que subjugam a dimensão humana a interesses mercantis, poderão ser quebrados, para que, enfim, a felicidade das pessoas seja mais importante que o limite do seu cartão de crédito. Parece que a solução é um ataque à raiz do problema, que é o sistema capitalista industrial, moderno, globalizado, neoliberal, a partir do entendimento de que é preciso pensar em um novo padrão de civilização, baseado em outras formas de produzir, consumir e viver.

\section{REFERÊNCIAS}

BAUDRILLARD, Jean. A sociedade de consumo. Lisboa: Edições 70, 1995.

BAUMAN, Zygmunt. Vida a crédito: conversas com Citlali Rovirosa-Madrazo. Rio de Janeiro: Jorge Zahar, 2010.

Amor líquido: sobre a fragilidade dos laços humanos. Rio de Janeiro: Zahar, 2004.

BITTENCOURT, Ricardo Nunes. A fragilidade das relações humanas na pósmodernidade. Espaço Acadêmico, v. 100, p. 62-69, 2009.

BRUCKNER, Pascal. A euforia perpétua: ensaio sobre o dever da felicidade. Rio de Janeiro: Difel, 2002.

BRUNELLI, Anna Flora. Ilusão à venda: discutindo a língua portuguesa. Escala 
Educacional, v. 3, n. 13, p. 34-41, 2008.

CAMPOS, Cristiana Caldas Guimarães de; SOUZA, Solange Jobim e. Mídia, cultura do consumo e constituição da subjetividade na infância. Psicologia: Ciência e Profissão, v. 23, n.1, p. 12-21, 2003.

COSTA, Jurandir Freire. O vestígio e a aura: corpo e consumismo na moral do espetáculo. 4. ed. Rio de Janeiro: Garamond, 2005.

DEBORD, Guy. A sociedade do espetáculo. São Paulo: Ebooks, 2003.

Sociedade do espetáculo: comentários sobre a sociedade do espetáculo. Rio de Janeiro: Contraponto, 1997.

EPICURO. The essencial Epicuro: letters, principal doctrines, vatican sayings, and fragments. Anherst: Prometheus Book, 1993.

FURTADO, Celso. O mito do desenvolvimento econômico. Rio de Janeiro: Paz e Terra, 1996.

GASSENFERTH, Walter et al. Gestão de negócios e sustentabilidade. Rio de Janeiro: Brasport, 2015.

HORKHEIMER, Max; ADORNO, Theodor W. Dialética do esclarecimento: fragmentos filosóficos. Rio de Janeiro: Jorge Zahar, 1985.

LATOUCHE, Serge. O decrescimento: por que e como? In: LENA, Philippe; NASCIMENTO, Elimar Pinheiro do (org.). Enfrentando os limites do crescimento: sustentabilidade, decrescimento e prosperidade. Rio de Janeiro: Garamond, p. 45-54, 2012.

LESBAUPIN, Ivo. Por novas concepções de desenvolvimento. In: ASSOCIAÇÃO BRASILEIRA DE ORGANIZAÇÕES NÃO GOVERNAMENTAIS. Por um outro desenvolvimento. São Paulo: Abong, 2012. p. 37-48.

LIPOVETSKY, Gilles. A felicidade paradoxal: ensaio sobre a sociedade de hiperconsumo. São Paulo: Companhia das Letras, 2007. 
LÖWY, Michael. Crise ecológica, capitalismo, altermundialismo: um ponto de vista ecossocialista. Interfacehs, v. 4, n. 3, p. 132-140, set./dez. 2009.

MAX-NEEF, Manfred. Dei saber al compreender: el desafio de una economia ecológica. In: SCHATAN, Jacobo. Crecimiento o desarrollo. Santiago: Cepaur, 1991.

15ºminário Internacional em Busca da Excelência. Entrevista coletiva. Fundação Nacional da Qualidade (FNQ), abr. 2007. . ELIZALDE, Antonio; HOPENHAYN, Martin. Desenvolvimento à escala humana: concepção, aplicação e reflexões posteriores. Blumenau: Edifurb, 2012.

MEDEIROS, Caciane Souza de. O conceito de felicidade na mídia e o estímulo ao consumo permanente: a felicidade não tem preço? Sessões do Imaginário, v. 14, n. 21 , p. 35-42, 2009.

NORGAARD, Richard B. Development betrayed: the end of progress and a coevolutionary revisioning of the future. London: Routledge, 1994.

RICO, Santiago Alba. La miseria de la abundancia: para una psicología del consumidor. In: RICO, Santiago Alba. Capitalismo y nihilismo: dialéctica del hambre y la mirada. Madrid: Akal, p. 159-186, 2007.

ROMÃO, Arquilau Moreira. Filosofia, educação e esclarecimento: os livros de autoajuda para educadores e o consumo de produtos semiculturais. Tese (Doutorado em Educação) - Universidade Estadual de Campinas, São Paulo, 2009.

RÜDGER, Francisco. Literatura de auto-ajuda e individualismo: contribuição ao estudo da subjetividade na cultura de massa contemporânea. 2. ed. Porto Alegre: Gattopardo, 2010.

SACHS, Jeffrey. Introduction. In: HELLIWELL, John; LAYARD, Richard; SACHS, Jeffrey (ed.). World Happiness Report. Columbia University: The Earth Institute, p. 2-9, 2012.

SACHS, Wolfgang (ed.) Dicionário do desenvolvimento: guia para o conhecimento como poder. Petrópolis: Vozes, 2000. 
SCHOPENHAUER, Arthur. Aforismos para a sabedoria de vida. 2. ed. São Paulo: Martins Fontes, 2006.

URA, Dasho Karma; ALKIRE, Sabina; ZANGMO, Tshoki. Case study: Bhutan Gross National Happiness and the GNH index. In: HELLIWELL, John; LAYARD, Richard; SACHS, Jeffrey (ed.). World Happiness Report. Columbia University: The Earth Institute, 2012. p. 108-158. 